\title{
A identificação nas organizações da economia solidária: entre a solidariedade e a competição
}

\author{
Financial management of a cooperative agro industry: practice management and fi- \\ nancial review
}

\begin{abstract}
Resumo
Com o objetivo de possibilitar o debate sobre o processo de identificação dos associados com as organizações que compõe a chamada economia solidária, este artigo de natureza teórica, apresenta os conceitos de identidade e identificação assim como descreve as características e os princípios defendidos pela economia solidária, buscando uma articulação entre as duas temáticas. Como resultado desta análise, observa-se que a teoria da identificação pode subsidiar fortemente o entendimento sobre o engajamento dos associados na proposta citada uma vez que neste contexto pode ser comum o conflito elou a dissonância cognitiva dos envolvidos por se inserirem em uma organização cuja identidade organizacional almejada é orientada por princípios e valores que divergem dos praticados nos demais espaços sociais e de trabalho.
\end{abstract}

Palavras-Chave: Identidade. Identificação. Economia Solidária.

\begin{abstract}
With the aim of propose the discussion regarding the identifying process among the associated with organizations that comprise the so-called solidary economy, this theoretical article presents the concepts of identity and identification as well as describes the characteristics and principles defended by the solidary economy, aiming an articulation between two themes. As a result of this analysis, it is observed that the theory of identification can strongly support the understanding of the member's engagement in the mentioned proposal, as in this context may be common the existence of conflict and/or the cognitive dissonance of the participants as they are inserted into an organization whose organizational identity is guided by principles and values that differ from those practiced in other social and working spaces.
\end{abstract}

Keywords: Identity. Identification. Solidary Economy.

Recebido: 08/12/2014 Aceito: 17/06/2015

\footnotetext{
Naldeir dos Santos Vieira ${ }^{1}$, Airton Cardoso Cançado ${ }^{2}$ e Rumeninng Abrantes Dos Santos ${ }^{3}$

${ }^{1}$ Universidade Federal dos Vales do Jequitinhonha e Mucuri, Doutorando em Administração aldeir.vieira@ufvjm.edu.br

2 Universidade Federal do Tocantins, Doutor em Administração - airtoncardoso@ yahoo.com.br

${ }^{3}$ Universidade Federal do Tocantins, Mestrado em Administração - rumeninng@ mail.uft.edu.br
} 
A identificação nas organizações...

\section{Introdução}

$\mathrm{C}$ omo a Economia Solidária resulta da ação de uma diversidade de organizações cuja que divergem dos adotados pelas demais organiza que divergem dos adotados pelas demais organizações capitalistas, espera-se que estas organizações sejam protagonistas de processos que desencadeiem em alterações da identidade dos sujeitos envolvidos uma vez que militam pela prática de relações produtivas que divergem das do padrão capitalista de produção. No entanto, esta dualidade entre trabalho embasado na solidariedade, porém cerceado por todo um contexto de "mercado" pode desencadear em conflitos de identidade e dissonância cognitiva, impactando fortemente na identificação dos envolvidos com a organização que fazem parte.

Como será abordado em seções posteriores, as organizações da economia solidária desenvolvem atividades produtivas, porém focam nas pessoas que participam deste processo e não no capital envolvido. Dentre seus objetivos, está a defesa dos interesses de seus integrantes que vão além da maximização do lucro que pode ser auferido. A ideia é que, por meio da solidariedade e da cooperação, os indivíduos possam se organizar em um novo modelo de gestão mais dialógico e democrático que possibilite a emancipação, o trabalho e obtenção de renda de forma coletiva.

Nesta lógica, está implícito que novas posturas são esperadas dos indivíduos, que em sua maioria são educados e aculturados em uma dinâmica capitalista, que envolve todos os aspectos da vida, caracterizada pela competitividade, individualidade, acumulação, isolamento e assimetrias de poder e em que impera as ações baseadas na racionalidade instrumental em detrimento de uma racionalidade substantiva (RAMOS, 1981; TENÓRIO, 2008; CANÇADO; PEREIRA; TENóRIO, 2013).

Deste modo, é natural que se evidencie o seguinte questionamento, diante da realidade apontada: como a teoria sobre a identidade e a identificação pode facilitar o entendimento do processo de identificação dos associados de organizações solidárias? Em decorrência, este trabalho de natureza teórica, tem como objetivo possibilitar o debate sobre o processo de identificação de associados de organizações da economia solidária.

Para além desta introdução, o trabalho segue estruturado com a seção que discorre sobre a identidade e o processo de identificação e, posteriormen- te, com a seção sobre os conceitos, características e princípios da economia solidária. Por fim, é traçado um paralelo entre as duas temáticas.

\section{A construção da identidade e a identifica- ção}

Em um estudo que se pretende analisar questões relacionadas à identificação em organizações da economia solidária, um construto que está diretamente relacionado à temática é o da identidade. Os estudos sobre a identidade focam no processo em que o indivíduo constrói seus valores, pensamentos, sentimentos tanto no âmbito societal, quanto organizacional e atraem pesquisadores de diversas áreas, com destaque para a sociologia, a psicologia social, a antropologia e a psicanálise.

Como pode ser observado em Laurentti e Barros (2000), o conceito de identidade se refere à relação do ser humano consigo mesmo e com as demais pessoas que circundam seu meio social. Deste modo, ela só pode ser compreendida se consideradas as relações entre indivíduos. Como a identidade é socialmente construída, não é possível separar o indivíduo do seu conjunto humano. Tajfel (1978 apud Rodrigues, 1997) considera que no nível individual, a identidade provém do sentido que o indivíduo atribui à sua interação com grupos socialmente diversos ao longo de sua vida, sendo que o significado específico de cada um desses grupos de referência varia com a importância relativa das experiências de interação para a construção ou afirmação da autopercepção.

No contexto organizacional, Carrieri, Fernandes e Marques (2009) consideram que a identidade é uma construção pessoal compreendendo as crenças compartilhadas pelos membros sobre o que é central na organização. Assim, na visão de Carrieri, Davel e Paes de Paula (2008), o indivíduo, uma vez inserido em uma estrutura organizacional, constrói sua identidade em relação à organização e outras categorias, como grupos de trabalho, ao interagir com os demais. Para Tajfel (1982) a identidade grupal se dá por fatores cognitivos, por meio do senso de pertencimento, por fatores valorativos resultantes da comparação entre o senso de pertencimento e os valores da organização; e pelo investimento emocional nos dois fatores anteriores.

Do conceito de identidade grupal, Pratt e Foreman (2000) avançam para o conceito de identidade 
organizacional que compreendem as características de uma organização consideradas por seus membros como fundamentais, distintivas (próprias) e duradouras (persistindo na organização ao longo do tempo). No entanto, Gioia, Schultzs e Corley (2000) afirmam que a identidade organizacional, apesar de duradoura, é relativamente dinâmica sendo sua durabilidade algo ilusório. Ao mesmo tempo em que retém crenças e valores centrais que se estendem ao longo do tempo e contexto, podem ser identificadas alterações nas interpretações e significados que caracterizam determinada identidade organizacional.

Por outro lado, a imagem organizacional diz respeito à forma como os membros da organização acreditam que os outros a veem, assim como à forma como a "elite organizacional" deseja que terceiros vejam a organização. A imagem em seus aspectos múltiplos permite que os membros da organização reflitam sobre a organização que querem construir em um determinado contexto social. Deste modo, com frequência atua como uma força que desestabiliza a identidade, requerendo constantemente que os membros reinventem e reconstruam o senso organizacional de si mesmos frente ao que é percebido por atores externos. As informações transmitidas por terceiros com impressões transitórias inesperadas ou problemas com a reputação da organização levam seus membros a repensarem sua identidade na busca por construção da imagem pretendida (Gioia; Schultzs; Corley, 2000).

Por fim, outro conceito oriundo das teorias sobre a identidade é o de identidade corporativa. Uma identidade corporativa denota um conjunto de atributos que os gerentes seniores ou grupo de interesses que centraliza o poder buscam atribuir à sua organização (Rodrigues; Child, 2008). Gioia, Schultzs e Corvey (2000) consideram que a identidade corporativa refere-se à representação direcionada da empresa, objetiva, constituída por meio formal de comunicação, enquanto que a identidade organizacional é subjetiva, informal, formada pelo compartilhamento de crenças e valores das pessoas. Ou seja, enquanto a identidade corporativa diz respeito à identidade esperada pela gestão (ou grupos) estratégica da organização, a identidade organizacional diz respeito ao que é praticado e percebido por seus membros, estando diretamente vinculada à cultura organizacional. Como afirma Rodrigues (1997), cultura e identidade são inter-relacionadas e interdependentes, à medida que uma necessita da outra como fonte de significados. Dessa forma, quanto maior a sincronia entre a identidade corporativa, identidade organizacional e identidade pessoal, maior a força do processo identificatório.

Apesar dos estudos serem incipientes na teoria organizacional, é com os resultados de estudos sobre o processo identificatório que surge o conceito de identificação, sendo esta definida como um processo em que o indivíduo percebe semelhanças entre suas crenças, opiniões e valores em relação a outros indivíduos ou organizações. A identificação ou processo identificatório pode ser entendido como uma linha contínua entre o eu e o outro, os quais se encontrariam potencialmente em pontos de inteira convergência, sem, entretanto, confundirem-se (FERNANDES, 2008).

Considerando o contexto organizacional, o sentimento de identificação cria um vínculo entre o indivíduo e a organização, um sentimento de pertencimento, despertando o desejo de participar e contribuir para com ela. Em decorrência, o conceito de identificação foi ampliado para o de identificação organizacional que congrega alguns aspectos relacionados a alteração no self, permitindo que a pessoa perceba seus valores e crenças mais semelhantes aos da organização, estabelece o senso de pertencimento e ocorre quando as crenças dos sujeitos sobre a organização tornam-se referências para a sua autodefinição (FERNANDES, 2008).

Em relação à identificação dentro de e entre grupos, Tajfel (1982) argumenta que os indivíduos utilizam-se de estereótipos para identificar e relacionar-se com os grupos externos.

Nesta relação intergrupos, o autor destaca duas características importantes para os grupos internos: as uniformidades no comportamento dos membros do grupo e as atitudes em relação aos grupos externos. Quanto mais distante do "interpessoal", isto é, quanto mais uniforme é o grupo, mais "diferente" o grupo externo é percebido. Isso influencia o fenômeno da personalização ou desumanização no qual o grupo externo não é reconhecido, e muitas vezes, hostilizado.

As concepções sobre grupos externos são geradas no seu contexto social e histórico e transmitidas para os membros dos grupos e perpassada por uma variedade de influências sociais. Em situação de competição entre grupos, existe a tendência de comportamento de favorecimento dos grupos internos. Isso é determinado pela necessidade de preser- 
var e/ou proteger o grupo, assim como, de alcançar uma identidade social positiva de seus membros (TAJFEL, 1982).

Dutton et al. (1994) argumentam que quanto mais atrativa a identidade organizacional, mais forte é a identificação do indivíduo com a organização. Uma identidade organizacional atrativa, possibilita ao indivíduo um forte senso de pertencimento favorecendo o engajamento do mesmo. Em relação ao grau de identificação dos indivíduos com os grupos ou organizações, Kreiner e Asforth (2004) apontam dois extremos do processo identificatório variando em um continuum desde a superidentificação à desidentificação. Além destes extremos, os autores citam também as formas ambíguas e neutras de identificação.

A desindentificação ocorre quando um indivíduo define a si mesmo como não tendo os mesmos atributos ou princípios que ele acredita serem definidores da organização (KREINER; ASFORDTH, 2004). Elsbach (1999) afirma que a desidentificação é uma separação ativa entre o indivíduo e a organização, não apenas uma coincidência ou desavença de atributos. Isso pode envolver uma rejeição à cultura da organização, missão, entre outros aspectos que ativam conscientemente a separação das identidades. Um indivíduo pode desindentificar totalmente ou desidentificar-se somente de pontos específicos da organização. Enquanto a identificação consiste em uma conexão geralmente positiva do sujeito com aspectos da organização, a desidentificação consiste em uma desconexão (KREINER; ASFORDTH, 2004).

Kreiner e Asfordth (2004) apontam que as organizações tendem a ver a desidentificação como algo indesejável, por representar a existência de conflitos entre o indivíduo e a organização. Sob esta ótica, a desidentificação é associada ao aumento dos custos com turnover e a visões negativas sobre dos funcionários sobre a organização que permanecem nela apenas se não houver melhores oportunidades. Entretanto, nem toda desidentificação é prejudicial à organização. A desidentificação, por possibilitar o conflito cognitivo, possibilita o questionamento e o desencadeamento de mudanças de comportamento, da inovação e de maior consciência crítica.

Como pode ser observado em Fernandes (2008), tanto a superidentificação quanto a desidentificação pode ser prejudicial ao indivíduo e à organização. A superidentificação constitui o outro extremo do con- tinuum e pode gerar comodismo no indivíduo que, em um ambiente de mudança, torna-se incapaz de enxergar as ameaças do ambiente.

Kreiner e Asfordth (2004) acreditam ser possível ainda a identificação e a desidentificação simultânea sobre os mesmos aspectos da organização. Isso se dá pelo fato destes aspectos tenderem a ser multifacetados, o que pode gerar sentimentos mistos sobre a organização. Deste modo, um indivíduo, tendo em vista o corte de custos, pode identificar-se com o corte por interpretá-lo como uma política de investimento em eficiência, mas ao mesmo tempo, desindentificar-se com a negligência à qualidade que pode resultar da mesma ação.

Para Kreiner e Asfordth (2004), diante da complexidade e dos equívocos das organizações modernas, caracterizadas pela perda dos valores, objetivos, e crenças dos indivíduos, uma pessoa pode se identificar e desidentificar com uma organização simultaneamente. Os autores denominam este tipo de identificação de ambivalente, esquizoidentificação ou conflituosa. Ademais, as organizações com múltiplas identidades ou identidades híbridas, ainda que não contraditórias ou partilhadas pelos membros, estão positivamente relacionadas à ambivalência.

Por fim, a identificação neutra ocorre quando a autopercepção de uma pessoa pode ser baseada em uma explicita abstenção de identificação ou desindentificação com a organização (KREINER; ASFORDTH, 2004). Como resultado, o indivíduo que se considera neutro em relação à organização pode se sentir ou se tornar menos engajado do que os demais que possuem senso de identificação. Além disso, observa-se que o individualismo tem relação positiva com a identificação neutra e representa uma tendência atual da carreira diante do contexto da empregabilidade e da flexibilidade.

\section{A economia solidária}

Como um movimento originário da sociedade civil, a economia solidária resulta de interações entre diferentes atores na busca por geração de trabalho e renda para os excluídos do mercado formal de trabalho e por relações econômicas, políticas e sociais orientadas pela sustentabilidade social, econômica e política (PEDRINI; OLIVEIRA, 2007; MONJE-REYES, 2011). 
O surgimento da economia solidária é marcado pela crise do mundo do trabalho e pelo posicionamento dos trabalhadores e sociedade civil organizada frente aos reflexos da acumulação flexível (SINGER, 2002; FRANÇA FILHO; LAVILLE, 2004). Na visão de Pedrini e Oliveira (2007), ela é fruto da solidariedade popular e das lutas pela emancipação de determinados grupos e comunidades. Atualmente, conta com o envolvimento de diversos atores sociais que integram a proposta baseada nos valores de cooperação, autogestão, sustentabilidade econômica e solidariedade.

Em relação à realidade brasileira, sua emergência se dá a partir da década de 80 e se intensifica na década de 90 , com a expansão do projeto neoliberal e com a crise do trabalho, impactando em elevados índices de desemprego, no aumento da informalidade, na flexibilização das relações e das condições laborais e desregulamentação dos direitos trabalhistas (PEDRINI; OLIVEIRA, 2007).

Gaiger (2004) complementa que a expansão das iniciativas de economia solidária no Brasil resulta da pressão sofrida por seus protagonistas diretos diante da crise estrutural do mercado de trabalho motivando as ações mobilizadoras de movimentos sociais, de parcelas do sindicalismo e de inúmeras entidades civis, na direção de soluções coletivas. Ademais, as articulações e apoio das esferas de governo e da sociedade civil reforçam o desenvolvimento destes empreendimentos.

Natividade et al. (2011, p.10) argumentam que as discussões sobre a economia solidária "voltamse, sobretudo, para a possibilidade de inclusão e emancipação do indivíduo em situação de vulnerabilidade econômico-social, que se vislumbra a partir da perspectiva de se sustentar com o próprio trabalho e das relações sociais que se estabelecem a partir desse".

Assim, como pode ser identificado em MonjeReyes (2011), a concepção da economia solidária se dá dentro do capitalismo dominante caracterizado pela exploração dos operários diante da busca por maximização dos lucros e da produção de riqueza. Citando Singer (2003), o autor afirma que a economia solidária pode ser definida como um conjunto de atividades econômicas de produção, consumo e crédito organizadas sobre a base de formas de autogestão, onde a propriedade do capital é coletiva e a tomada de decisões é democrática tendo em vistas a participação direta de todos os membros da entida- de. "En esta definición todos los trabajadores son propietarios del negocio, ya que el capital es su propia capacidad transformación material, y todos trabajan para producir. Por tanto en esta forma de producción, la división capital-trabajo tiende a desaparecer" (MONJE-REYES, 2011, p.706, grifos do autor).

Estão incorporados ao termo "economia" apenas os empreendimentos geradores de renda e trabalho ou ligados diretamente a esses como as cooperativas ou ainda os clubes de troca. Excluem-se deste grupo todas as associações sem fins lucrativos que não produzem renda para seus associados e todas as organizações cujo objetivo se limita ao bem-estar dos seus sócios, faltando-lhes a dimensão política de produzir novas relações sociais em vista de uma mudança de sociedade (LECHAT, 2002).

Dentre os benefícios da economia solidária destaca-se o fato destes empreendimentos possibilitarem o envolvimento dos trabalhadores com "a dinâmica local, com os espaços de debate público, de decisão e de organização social. Esse envolvimento fundamenta-se na perspectiva de construir relações democráticas, participativas e nos processos de politização que vão se constituindo" (PEDRINI; OLIVEIRA, 2007, p.112).

Gaiger (2004) complementa que estas organizações minimizam a presença de relações assalariadas e provocam envolvimento dos indivíduos com os problemas da comunidade e com as lutas pela cidadania; tendem a criar ou reforçar inúmeras instâncias de mediação e representação, tais como uniões associativas, federações cooperativas, redes de intercâmbio e organizações de fomento. Além disso, por sua inserção social e comunitária, cumprem uma série de funções, em saúde, educação, defesa de minorias e preservação ambiental e envolvem as pessoas na busca por desenvolvimento humano integral, individual, social e ecológico contribuindo para a formação de identidades culturais.

Dentre os princípios da economia solidária, Monje-Reyes (2011) destaca a solidariedade entre trabalhadores que é a base social para a produção coletiva de bens e serviços, reorganizando a forma de produção por meio de cooperativa, pequenas empresas autogestionadas e organizações associativas informais. Para Silva et al. (2011) é com a solidariedade e com a valorização do bem comum entre membros de uma determinada comunidade que torna-se possível o exercício da reciprocidade nas re- 
lações. O segundo princípio destacado por MonjeReyes (2011) é a igualdade entre pares sobre uma propriedade coletiva que é gerida por meio de técnicas e práticas democráticas de tomada de decisão. Para Pedrini e Oliveira (2007), a autogestão fortalece o sentimento de pertença dos trabalhadores, por meio da transparência, da comunicação e da coresponsabilidade.

Conforme Pedrini e Oliveira (2007, p.113-114), a economia solidária apresenta as seguintes categorias principais:

- pauta-se pela propriedade coletiva dos meios de produção e dos resultados da produção, pela prática da autogestão, pela apreensão de todo o processo produtivo por todos os trabalhadores, pela valorização de cada pessoa, pela construção do coletivo, pelo compromisso com os outros trabalhadores e pelo enfrentamento das diferenciadas expressões da questão social;

- está comprometida com a sustentabilidade social que refere-se ao caráter distributivo da riqueza produzida, evidenciando e valorizando o ser e não o ter; com a sustentabilidade ecológica que diz respeito à diminuição dos impactos da ação humana;

- caracteriza-se pela valorização do trabalho humano como fonte de fortalecimento dos vínculos sociais entre os participantes, desenvolvendo o potencial criativo, educacional e cultural de todos;

- repensa o econômico com cunho social, reavaliando o impacto da economia na vida das pessoas e fortalecendo as políticas de enfrentamento à pobreza. Apresenta-se como uma alternativa viável para a geração de trabalho e renda, e para a satisfação direta das necessidades de todos, organizando a produção e a reprodução da sociedade de modo a eliminar as desigualdades materiais e sociais;

- tem como premissa a politização das dimensões da vida, compreende a importância da política para a democratização do saber, da propriedade, da tecnologia, da vida;

- é um vetor do desenvolvimento sob bases sustentáveis, ao possibilitar o empoderamento dos sujeitos, da sociedade civil, tem sua gênese no território e enaltece valores como a autonomia, democracia e participação;

- utiliza a articulação em rede como uma de suas estratégias, que se expressa em vários formatos: rede de colaboração solidária, rede de trocas, rede de ajuda mútua, rede de redes, rede de agências de fomento, rede de economia solidária;
- é um movimento que está em conexão com outras formas de revindicações (reforma agrária, segurança alimentar e nutricional, agroecologia) e com outros movimentos sociais (feministas, ecológicos, negros), possibilitando a troca de experiências, a busca coletiva de alternativas e principalmente o enfrentamento a todas as formas de opressão.

Com efeito, ainda que o trabalho seja um dos valores centrais da economia solidária, ao buscar-se a unidade entre produção e reprodução, busca-se evitar a contradição fundamental do sistema capitalista, que desenvolve a produtividade, mas exclui crescentes setores de trabalhadores do acesso aos seus benefícios. Além disso, na proposta da economia solidária, a eficiência não pode limitar-se aos benefícios materiais de um empreendimento, mas se define também como eficiência social, em função da qualidade de vida e da felicidade de seus membros (TEREZAZUCHETTI, 2011, p.8).

Desse modo, na medida em que apresenta alternativas viáveis para a geração de trabalho e renda e para a satisfação direta das necessidades de todos, buscando provar que é possível organizar a produção e a reprodução da sociedade de modo a eliminar as desigualdades materiais e difundir os valores da solidariedade humana, o campo da economia solidária pretende ser um poderoso instrumento de combate e reflexão sobre os mecanismos que geram a exclusão social (TEREZA-ZUCHETTI, 2011).

Em suma, como pode ser identificado em Silva et al. (2011), a dinâmica de trabalho e produção da economia solidária, de modo geral, valoriza a reciprocidade, a solidariedade, o respeito, a participação, a autonomia, a autogestão e a constituição de relações sociais e políticas, centradas na cooperação mútua, formalizadas sob a figura jurídica de associação ou cooperativa ou mesmo atuando de modo informal. Assim, Natividade et al. (2011) enfatizam que não se trata apenas de alcançar trabalho e renda, mas dar possibilidade de criar novas formas de trabalho e novos significados compartilhados que requalificam os sentidos do trabalho, da produção, do consumo e das trocas.

Apesar dos benefícios que podem ser auferidos com a trabalho desenvolvido pelas organizações que compõe a economia solidária, Paes-de-Paula et al. (2011) apontam uma diversidade de problemas enfrentados no interior destes empreendimentos, com destaque para: a resistência dos trabalhadores em assumir cargos diretivos, a pouca ou inexistente 
preocupação dos trabalhadores com a qualificação profissional e a baixa participação na tomada de decisões. Estes problemas estão diretamente associados a questões como a naturalização da opressão e a reprodução de práticas e valores capitalistas. Cançado (2007) reforça os desafios de se conseguir a autogestão de fato na organização.

Na visão de Paes-de-Paula et al. (2011, p.329) há incoerências e ambiguidades na Economia Solidária. "E isso pode ser bem demonstrado quando se leva em consideração o fato das cooperativas viverem inseridas dentro de um sistema capitalista, que se mostra hegemônico em diversas categorias econômica, política e ideológica". Tal fato provoca contradições que resultam nos seguintes problemas:

a) Problemas estruturais: divisão do trabalho, constituição de hierarquias, jornadas que excedem o tempo convencional, formação de quadros administrativos, decisões centralizadas nos "mais experientes";

b) Problemas de valores individualistas $\mathrm{x}$ solidários: a permanência do individualismo nas atitudes, nas distribuições de sobras e de tarefas; o desinteresse por participar das decisões;

c) Problemas gerenciais: dificuldade de resignificar o conhecimento ou o uso da técnica para o novo contexto autogestionário; com isso, em busca da eficiência, se reproduzem instrumentos técnicos para a coordenação da cooperativa;

d) Problemas políticos: ausência de fomento ou debate sobre valores da Economia Solidária, cooperativismo, associativismo, alienação, relações de poder no trabalho, bem como propostas de articulação de contraponto ao capitalismo;

e) Naturalização da opressão: a permanência e reprodução do discurso de que a sociedade sempre se estruturou de maneira hierárquica, e que o fato de haver desigualdade na distribuição de rendas e tomadas de decisão é pela falta de capacitação e conhecimento do indivíduo;

f) Sequestro do imaginário: a impossibilidade de se pensar em algo que transcenda o sistema capitalista, visto que se acredita que ele é "dominante" e o sujeito não tem voz, nem vez. Nega-se, com isto, a possibilidade de se criar utopias (PAES-DE-PAULA et al., 2011).

Assim, Paes de Paula et al. (2011) argumentam que a sobrevivência de um imaginário capitalista nas economias solidárias é um dos principais problemas enfrentados por estas experiências. Esta realidade é difícil de ser superada, uma vez que se manifesta de infinitas e sutis formas sendo mantida e atualizada em todo um ordenamento social, que socializa e naturaliza as pessoas nesta lógica de pensamento.

Nesta linha, Cançado (2007) argumenta que que a normalização da sociedade hierarquizada e a forte hegemonia do sistema capitalista, criado e recriado nestas bases é um grande desafio dos empreendimentos de economia solidária para a implantação da autogestão.

\section{Uma articulação inicial entre identificação e economia solidária}

Retomando as características que constituem a proposta da Economia Solidária, Pedrini e Oliveira (2007) e Paes-de-Paula et al. (2011) observam que o grande desafio da proposta está no desenvolvimento dessas práticas em uma realidade repleta da lógica capitalista. A inserção no movimento exige a busca por certa utopia e que os atores assumam em sua práxis esse desafio. Implica em transformações graduais e fundamentais das concepções e condições de vida, defendidas e geridas por seus pelos atores com insistente e permanente resistência, contestação e enfrentamento.

Para Tereza-Zuchetti (2011, p. 15), pensar a economia solidária supõe a capacidade de incorporar na prática dos atores novas linguagens e narrações. A economia solidária torna-se então "um espaço de promoção do diálogo intercultural, onde nem as culturas nem as identidades devem ser compreendidas como imutáveis, podendo ser revisadas e/ou modificadas".

A economia solidária representaria o espaço e lugar da comunicação e negociação, do encontro e desencontro e, finalmente, da convivência. Negar o conflito é impossibilitar o diálogo e toda possibilidade de comunicação. A interculturalidade é então uma pedagogia dos encontros, mas não dos encontros entre culturas e identidades perfiladas e sim entre a indefinição e o ambíguo das culturas e identificações dos sujeitos (TEREZA-ZUCHETTI, 2011, p.15).

Com a necessidade de posturas diferenciadas, o maior desafio, na visão de Tereza-Zuchetti (2011, p.800), está relacionado à superação de fronteiras sociais e geográficas e de limites mentais, políticos, institucionais, favorecendo "convergências inclusivas, de integração sistêmica da economia solidária, de modo a convertê-la em base social e econômica tangível de outro modelo de desenvolvimento". Caso contrário, não serão construídos ambientes e 
mecanismos de retroalimentação, e não é atingida a efetividade da proposta e o autêntico e inovador protagonismo social.

É indiscutível que a formação de empreendimentos da economia solidária possibilitará a criação de ambientes produtivos cujos princípios prezarão por relações de trabalho diferenciadas que influenciarão na (re)construção da identidade dos associados. No entanto, como pode ser observado nas teorias sobre identidade, com destaque para Rodrigues e Child (2008), a diversidade que caracteriza esses grupos pode impactar fortemente na presença de diferentes perfis de associados como resultado da presença de diferentes atributos, valores e visões de mundo, impactando na formação de uma identidade organizacional que não pode ser vista apenas sob o ângulo da convergência e da homogeneidade. É provável que esta identidade organizacional seja caracterizada pela fluidez (ver Carrieri, Davel e Paes-de-Paula, 2008) por influência de subgrupos que se utilizam da política como instrumento para a defesa de seus interesses, pressupostos e ideologias.

Como representantes de um movimento que se pauta por uma agenda social, as organizações de economia solidária são oxigenadas por uma militância principal que busca a afirmação de uma identidade corporativa caracterizada pela solidariedade, participação, cooperação, dentre outros princípios citados em seções anteriores. No entanto, para que esta identidade se torne organizacional, torna-se mister um mínimo de congruência entre as crenças, opiniões e valores de cada associado com os professados pelo movimento (FERNANDES, 2008). Caso contrário, este contexto passa a ser caracterizado pela desindentificação, ambivalência ou identificação neutra.

Se por um lado a superidentificação dos associados pode levá-los a um engajamento com as propostas da economia solidária, para que isto aconteça, torna-se necessário o máximo de congruência entre as identidades pessoais, organizacional e corporativa. Por meio dessa congruência, torna-se possível a efetivação de práticas autênticas e um protagonismo social realmente impactante permitindo a construção de uma imagem de organização que represente verdadeiramente a ideologia do movimento.

Caso o associado, aculturado em um ambiente de competitividade e individualismo, tenha seus valores moldados por esta dinâmica, dificilmente se identificará com os princípios defendidos por um empreendimento solidário, tornando necessário um processo de socialização e de aprendizagem na prática social do trabalho, possibilitando reconfigurações da identidade. De outro modo, a organização será caracterizada por relações de ambivalência e/ou desindentificação dos associados em relação às ações propostas pelo empreendimento. Como bem apontam Paes-de-Paula et al. (2011, p. 325), "uma efetiva transformação social requer não apenas a construção de novas estruturas sociais, mas também a criação de um novo imaginário capaz de sustentar novas práticas e olhares sobre a realidade".

Por fim, caso o empreendimento seja a única alternativa para geração de renda a seus associados, não alterando a forma como o trabalho é realizado, assim como, a concepção do que venha a ser trabalho, produção, trocas e consumo, replica-se um quadro em que o único interesse relevante é a produtividade, sem a mínima aderência aos pressupostos mais profundos do movimento. Se a renda é o único fator que une os associados em torno do empreendimento, este só se comprometerá até o momento que obtiver uma oportunidade de maiores ganhos financeiros em outra atividade ou organização. Neste caso, a neutralidade em relação a identificação marcará a relação entre o indivíduo e a organização da qual faz parte.

Muitas vezes o membro do empreendimento de economia solidária não pode ser considerado "exatamente" como um militante do movimento da economia solidária. Geralmente, o papel de militante cabe a indivíduos que têm sua renda gerada em empreendimentos que, em geral, não podem ser classificados de economia solidária. Esta realidade cria um gap entre praticantes (pelos mais diversos motivos, inclusive a falta de alterativas) e militantes (por motivos ideológicos, na maior parte) da economia solidária, onde a identificação ou a superidentificação caberia mais ao segundo grupo que ao primeiro, porém, este segundo grupo não faz parte da organização em si, por mais que seja apoiador do empreendimento.

\section{Considerações finais}

Como a teoria sobre a identificação possibilita analisar o engajamento de integrantes das organizações ao esclarecer a relação entre identidade pessoal e identidade organizacional e seus desdobramentos, algumas questões que envolvem a prática, abran- 
gência, alcance e desafios enfrentados pelas organizações solidárias podem ser melhor compreendidas com o seu uso. A análise dos impactos da superidentificação, desindentificação, neutralidade e ambivalência neste contexto pode facilitar o desenvolvimento de ações consideradas como de relevância para o avanço do movimento e maximização de seus impactos.

Gioia, Schultzs e Corley (2000) apresentam a possibilidade para alterações da identidade organizacional cabendo aos responsáveis pelo processo de intervenção considerar os elementos aqui apresentados para maior efetividade de suas ações. Como a identidade corporativa é constituída por meio formal de comunicação em direção a uma identidade organizacional pretendida, os processos de intervenção nestes empreendimentos requer possibilitar o entendimento mútuo (HABERMAS, 1987) por meio da dialogicidade nas ações comunicativas, tendo em vista que ações teleológicas são comuns a organizações com hierarquias piramidais e caracterizadas por forte assimetria nas relações de poder.

Por envolver um conjunto de organizações apoiadoras, a imagem positiva das organizações da economia solidária pode ampliar a inserção de um número maior de atores, impactando no fortalecimento do movimento. Além disso, a percepção e feedbacks de grupos externos permitem que, internamente, o grupo se autodefina e reconstrua seu senso organizacional. Neste sentido, a construção e fortalecimento de redes, torna a economia solidária ainda mais abrangente ao se fortalecer por meio da intercooperação. Se por um lado, as ações de grupos isolados em meio a um conjunto de organizações mercantis reforçam a continuidade de práticas afeitas ao modelo hegemônico de produção. De outro modo, ações articuladas em redes fortalecem a construção de um senso de pertencimento, facilitando a visualização de referências para autodefinição da identidade dos grupos articulados.

Estão nas relações com grupos externos as maiores possibilidades dos associados se distanciarem dos valores defendidos pela economia solidária o que requer compreensão da missão organizacional e coesão interna, para que percebam as fronteiras organizacionais e a natureza das práticas que são desenvolvidas em cada contexto. Isto só é possível com estímulo ao desenvolvimento da consciência crítica e da coesão interna, o que requer transparên- cia e simetria na comunicação e definições de metas coletivas.

Neste sentido, pensar a realidade da América Latina é pensar em uma diversidade de grupos excluídos que veem na economia solidária uma alternativa para o acesso às mínimas condições para a sobrevivência e têm sua identidade moldada pela luta constante contra a exclusão. Já ao norte, observa-se no contexto europeu uma economia de mercado abalada pela escassez de emprego, possibilitando o surgimento de grupos que se identificam pela garantia de atividades laborais e manutenção da qualidade de vida. Este quadro mostra a relevância em se pensar políticas públicas de apoio aos empreendimentos solidários em ambos os contextos, no entanto a teoria sobre a identidade organizacional alerta para a necessidade da organização espontânea destes grupos. Ao forçar a criação destes grupos sem a mínima identificação de seus integrantes com os valores da economia solidária, dificilmente se chegará a organizações que se sustentem no longo prazo. As atividades de intervenção tornam-se necessárias, porém no sentido de possibilitar informações válidas e úteis, a escolha livre e informada, e por fim, o comprometimento interno dos envolvidos.

As questões apontadas mostram o quão fundamental é compreender as questões subjetivas que envolvem os empreendimentos solidários. No entanto, estudos que consideram os aspectos relacionados à identidade e identificação neste campo específico são extremamente raros e incipientes. Esta realidade pode ser ilustrada pelo fato de não se ter identificado na base de dados do Spell (Scientific Periodicals Eletronic Library) e do Google Acadêmico artigos que tratem diretamente a articulação entre os dois construtos, sinalizando para a existência de uma lacuna a ser explorada pelos estudos organizacionais. Em decorrência, é proposta como possibilidade para estudos futuros a realização de estudos empíricos em organizações da economia solidária que abordem aspectos relacionados à (re)construção da identidade e ao processo identificatório neste contexto.

\section{Referências}

CANÇADO, A. C.; PEREIRA, J. R.; TENÓRIO, F. G. Gestão social: epistemologia de um paradigma. Curitiba: CRV, 2013, 216p. 
CANÇADO, A. C. Autogestão em cooperativas populares: os desafios da prática. Salvador: IES, 2007.

CARRIERI, A. P.; DAVEL, E.; PAES-DEPAULA, A. P. Identidade das organizações: múltipla? fluida? Autônoma? Organização \& Sociedade, v. 15, n. 45, p. 127-144, 2008;

; FERNANDES, M. E. R.; MARQUES, A. L. Identidade organizacional e os componentes do processo de identificação: uma proposta de integração. Cadernos EBAPE, v.7, n.4, p.688703, 2009.

DUTTON, J. E.; DUKERICH, J. M.; HARQUAIL, C. V. Organizational Images and Member Identification. Administrative Science Quarterly. V. 39, n. 2, uun. 1994, p. 239-263;

ELSBACH, K. An expanded model of organizational identification. Research in Organizational Behaviour. v. 21, p. 163-200, 1999.

FERNANDES, M. E. R.. De "Jóia da Coroa" a "Coroa sem Jóia" estudo do processo identificatório em duas empresas multincionais em reestruturação. Belo Horizonte. UFMG. Tese de Doutorado. 2008.

FRANÇA FILHO, G. C.; LAVILLE, J. Economia solidária: uma abordagem internacional. Porto Alegre: Editora da UFRGS, 2004.

GAIGER; L. I. A Economia Solidária e o Projeto de Outra Mundialização. Dados - Revista de Ciências Sociais, v. 47, n. 4, 2004, pp. 799 - 834;

GIOIA, D. A.; SCHULTZ, M.; CORLEY, D. K. Identity, image and adaptive instability. Academy of Management Review. v. 25, p. 63-81, 2000.

HABERMAS, J. Teoría de la acción comunicativa I: Racionalidad de la acción y racionalización social. Madrid: Taurus, 1987.

KREINER, G. E.; ASHFORTH, B. E. Evidence toward an expanded model of organizational identification, Journal of Organizational Behavior. 2004, 25, p. 1-27;
LAURENTTI, C.; BARROS, M. N. F. Identidade: questões conceituais e contextuais. Revista de Psicologia Social, v. 2, n. 1, jun. 2000;

LECHAT, N. M. P. Economia social, economia solidária, terceiro setor: do que se trata? Civitas - Revista de Ciências Sociais. v. 2, n. 1, 2002;

NATIVIDADE, E. A.; PEREIRA, J. R.; OLIVEIRA, V. A. R. de. Gestão Social de Políticas Públicas de Geração de Trabalho e Renda: uma reflexão por meio das ações da Secretaria Nacional de Economia Solidária. APGS, Viçosa, v.3, n.1, pp. 1-22, 2011;

MONJE-REYES, P. Economía solidaria, cooperativismo y descentralización: la gestión social puesta en práctica. Cadernos EBAPE, v. 9, n. 3, 2011;

PAES-DE-PAULA, A. P.; et al. A Economia Solidária e a Questão do Imaginário: em busca de novas perspectivas. $\mathrm{O} \& \mathrm{~S}, \mathrm{v} .18$, n.57, p. 323333, 2011;

PEDRINI, D. M.; OLIVEIRA, A. L. de. A economia solidária como estratégia de desenvolvimento. Emancipação, v. 7, p. 111-133, 2007;

PRATT, M. G.; FOREMAN, P. O. Classifying managerial responses to multiple organizational identities. Academy of Management Review, 2000, v. 25, Issue 1;

RODRIGUES, S. B.; CHILD, J. Corporate Coevolution: a political perspective. London: John Wiley \& Sons. 2008. Cap 8. Corporate Identity.p 147-171;

SILVA, F. A. G. et al. Os Princípios de Economia Substantiva de Karl Polanyi em relações de Economia Solidária: o caso do povoado Cruz (Currais Novos/RN), RECADM, v. 10, n. 2, p. 93106, 2011.

SINGER, P. Introdução à economia solidária. São Paulo: Fundação Perseu Abramo, 2002.

TAJFEL, H. Social psychology of intergroup relations, Annual Review of Psychology. v. 33, p. 139, 1982; 
TENÓRIO, F. G. Tem razão a administração? 3 Ed.

Ijuí: Editora da Unijuí, 2008.

TEREZA-ZUCHETTI, D. et al. Economia Solidária: uma experiência intercultural. Economía, Sociedad y Territorio, v. xi, n. 35, 2011, p. 1-17; 